\title{
PROYECTO DE TRADUCCIÓN DEL MUNDUS SYMBOLICUS DE FILIPPO PICINELLI EN EL CENTRO DE ESTUDIOS DE LAS TRADICIONES DEL COLEGIO DE MICHOACÁN
}

\author{
BÁRBARA SKINFILL NOGAL \\ Centro de Estudios de las Tradiciones, El Colegio de Michoacán
}

Aceptado: 21/12/2020

\section{RESUMEN}

El objetivo de este trabajo es dar a conocer el proyecto de traducción y edición de la enciclopedia de emblemas e imprese Mundus Symbolicus de Filippo Picinelli que se lleva a cabo en el Centro de Estudios de las Tradiciones de El Colegio de Michoacán. Así, la traducción permitirá al lector moderno y, en especial, a los historiadores del arte descifrar los significados latentes de los símbolos empleados en la producción plástica y literaria, así como en diversos espacios culturales en donde floreció la emblemática.

Palabras clave: Filippo Picinelli, emblemas, latín, traducción.

\section{ABSTRACT}

The objective of this work is to publicize the project of translation and edition of the encyclopedia of emblems and imprese Mundus Symbolicus by Filippo Picinelli that is being carried out in the Center of Studies of the Traditions of El Colegio de Michoacán. In this way, the translation will allow the modern reader, and art historians in particular, to decipher the latent meanings of the symbols used in literary and visual production, as well as in various cultural Spaces where the use of the emblematic language flourished.

Keywords: Filippo Picinelli, emblems, latin, translation. 


\section{ANTECEDENTES}

El Proyecto Maturino Gilberti, el Proyecto Curso de derecho canónico e indiano y el Proyecto Mundus Symbolicus son tres grandes proyectos colectivos de investigación del Centro de Estudios de las Tradiciones de El Colegio de Michoacán (Zamora, estado de Michoacán, México). Las tres investigaciones tienen como objetivo principal la traducción, edición y estudios de los textos; en el primer caso, del franciscano fray Maturino Gilberti quien escribió sus

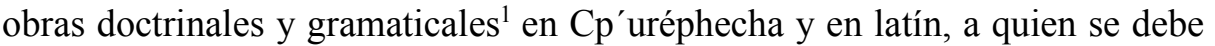
la primera gramática latina publicada en América, durante el siglo XVI; en el segundo y tercer caso, se realiza la traducción del Cursus Iuris Canonici et Indici del jesuita Pedro Murillo Velarde ${ }^{2}$ y del Mundus Symbolicus de Filippo Picinelli (1604-1686), ambos textos neolatinos que gozaron de una amplia difusión en la cultura novohispana y cuya influencia se extendió a principios del siglo XIX.

No es fortuito que el doctor Carlos Herrejón, estudioso del sermón novohispano, propusiera al doctor Andrés Lira, presidente de El Colegio de Michoacán, que se emprendiera el proyecto de traducción del Mundus Symbolicus. Según cuenta el maestro Eloy Gómez Bravo, don Luis González, fundador de nuestra institución y connotado historiador mexicano, realizó gestiones necesarias a fin de que se recibiera en comodato parte del fondo bibliográfico almacenado en el exconvento de Acolman (Estado de México), y a finales de 1986 llegó al Colegio de Michoacán ${ }^{3}$ un ejemplar del Mundus Symbolicus entre otros textos seleccionados.

1 Entre las cuales se ha publicado: GILBERTI, M., Vocabulario en lengua de Mechuacán (ed. y transcrip. de Agustín Jacinto ZAVALA), Zamora, El Colegio de Michoacán / Fideicomiso Teixidor, 1997; Grammatica Maturini (introd., ed., trad. y notas de LUCAS GONZÁLEZ, R.), Zamora, El Colegio de Michoacán, 2003; Thesoro spiritual en lengua de Mechuacan (trad., pres. y notas de MÁRQUEZ JOAQUÍN, P.), Zamora, El Colegio de Michoacán / Fideicomiso Teixidor, 2004; Arte de la lengua en Mechuacán (transcrip., ed. y notas de MONZÓN, C.), Zamora, El Colegio de Michoacán / Fideicomiso Teixidor, 2004; y el Diálogo de doctrina christiana en la lengua de Mechuacan (1559), (ed., introd., transcrip. y cotejo de FRANCO MENDOZA, M.), Zamora, El Colegio de Michoacán, 2006 (edición en CD).

2 MURILLO VELARDE, P., Curso de derecho canónico hispano e indiano (trad., ed., coord. del proyecto: Alberto CARRILLO), Zamora, El Colegio de Michoacán / Facultad de Derecho de la UNAM, 2004-2005 (4 vols.) (obra completa en español acompañada del texto latino en Curso de derecho canónico hispano e indiano, Zamora, El Colegio de Michoacán, 2008, edición en CD).

3 GÓMEZ BRAVO, E., «El proyecto de investigación Mundus Symbolicus en El Colegio de Michoacán» en SKINFILL NOGAL, B. y GÓMEZ BRAVO, E. (eds.), Las dimensiones del arte emblemático (Emblemata. Estudios de Literatura Emblemática), Zamora, El Colegio de Michoacán / Consejo Nacional de Ciencia y Tecnología, 2002, pp. 87-99 (p. 87). 


\section{Semblanza del equipo}

Así, desde 1987 se conformó un equipo de trabajo formado por investigadores de distintas disciplinas y con amplios conocimientos en la traducción del latín que, además de sus proyectos personales de investigación, colaborarían con el «Proyecto de Investigación Mundus Symbolicus». El equipo de investigadores fue coordinado por Eloy Gómez Bravo $(\dagger)$ y, en diversos momentos, ha estado formado por Rosa Lucas González, Alberto Carrillo Cázares ( $\dagger$ ), Herón Pérez Martínez (†), Heriberto Moreno García (†), Carlos Herrejón Peredo, Bárbara Skinfill Nogal y Pascual Guzmán.

Asimismo, se cuenta con la colaboración en la redacción de los estudios introductorios para nuestras publicaciones de investigadores procedentes de distintas especialidades e instituciones tanto nacionales, como internacionales. De El Colegio de Michoacán participan: Alberto Carrillo Cázares, Carlos Herrejón Peredo, Eloy Gómez Bravo, Herón Pérez Martínez, Agustín Jacinto Zavala, Bárbara Skinfill Nogal, Nelly Sigaut (CEH) y Salvador Álvarez (CER). También el proyecto fue recibido con buena disposición por los profesores de la Universidad Nacional Autónoma de México, quienes siempre lo han apoyado generosamente de diversas formas y han escrito introducciones para nuestros libros: Jaime Cuadriello (IIE), Lucero Enríquez (IIE), Arnulfo Herrera (IIE), Elena Isabel Estrada de Gerlero (IIE), Eduardo Gabriel Sánchez Barragán (FFyL); y la lista continúa con Héctor Santiesteban Oliva (Universidad de Baja California Sur). Para el proyecto ha sido muy importante contar con el apoyo de la Sociedad Española de Emblemática y la colaboración de sus asociados: Sagrario López Poza (Universidad de La Coruña, España), Víctor Mínguez (Universitat Jaume I, España), José Julio García Arranz (Universidad de Extremadura, España), Rafael García Mahíques (Universidad de Valencia, España), Fernando R. de la Flor (Universidad de Salamanca, España), Reyes Escalera Pérez (Universidad de Málaga, España), Antonio Bernat Vistarini (Universidad de las Islas Baleares, España) y John T. Cull (Holy Cross College of Worcester, Estados Unidos).

Desde 2006, Rosa Lucas González coordina el proyecto y, con la finalidad de avanzar en la traducción, aumentó el número de los traductores gracias a la invitación que se hizo a diversos investigadores para colaborar en el mismo. Además de las dos traductoras de El Colegio de Michoacán que actualmente participan, hay que mencionar a los traductores de la Universidad Nacional Autónoma de México: Tania Alarcón Rodríguez (FFyL), María Leticia López Serratos (FFyL), Yamarasbeth Marina Belén Díaz González (FFyL), Iván salgado García (FFyL), Antonio Río Torres-Murciano (ENES, Morelia); y, finalmente, 
también colaboran Cirilo García Román (Universidad del País Vasco, España/ Sociedad Española de Emblemática) y Héctor Velázquez Fernández (Universidad Popular Autónoma del Estado de Puebla).

\section{El Mundus Symbolicus}

En lo relativo a la obra que nos ocupa, el Mondo Simbolico (Milano, 1653), podemos decir que es una extensa enciclopedia de emblemas del siglo XVII que ha tenido gran importancia desde su época, pues dicha obra en italiano, su lengua original, contó con ocho ediciones $\left(1669,1670^{*}, 1678^{*}\right.$ y 1680$)$, y muy tempranamente se tradujo al latín, con el nombre de Mundus Symbolicus, la cual también se editó seis veces más $(1681,1687,1694,1695,1715$ y 1729). La traducción contribuyó en gran medida a su amplia difusión y repercusión en los distintos ámbitos de la cultura europea, americana y, en especial, la novohispana de los siglos XVII, XVIII y principios del XIX.

El Mundus Symbolicus a nuestros ojos se presenta como un repertorio de erudición que, por su contenido, proporciona noticias de muy variada índole hasta el siglo XVII, época de su redacción y traducción al latín-; entre estas noticias destacan las históricas, geográficas, astronómicas, zoológicas, botánicas, médicas, mecánicas, literarias, musicales, matemáticas, religiosas, morales, fantásticas, científicas, etcétera, que fueron convalidadas, según Picinelli, por las citas de «respetabilísimas opiniones y documentos» de autores de la Antigüedad, de la Edad Media y de la Edad Moderna, tanto sagrados como profanos. La obra consta de 25 libros que están distribuidos en dos mundos: el «Natural», creado directamente por la mano de Dios, y el «Artificial», creado también por Dios, sólo que a través de la mano del hombre. En el primer mundo, los libros I-XIII abordan la naturaleza y están dedicados a los cuerpos celestes; los cuatro elementos; los dioses y héroes (de la mitología clásica), y hombres (que aparecen en la Biblia); las partes del cuerpo; los animales aéreos, terrestres y marinos; las hierbas, las flores y los árboles; las gemas y los metales. En el segundo mundo, libros XIV-XXV, encontramos libros dedicados a varios tipos de instrumentos artificiales, entre los cuales hallamos los eclesiásticos, domésticos, mecánicos, lúdicos, náuticos, matemáticos, militares, musicales y agrícolas; junto con las partes de los edificios, las letras del alfabeto y los cuerpos mixtos. (Figs. 1 y 2).

Esta obra, además, se inserta en el ámbito de la literatura emblemática, caracterizada por la combinación de un lenguaje icónico-literario, que en sus inicios, «bajo la apariencia de un juego [de ingenio] y mediante el uso de un 
código de imágenes visuales y de sentencias escritas, [...transmitieron] mensajes de muy distinta índole»; este sistema de comunicación tuvo

«(...) gran importancia en una sociedad predispuesta de antemano a aceptarlo, tras siglos de familiaridad con el universo de los símbolos. El emblema se convierte así en el testimonio del gusto de una época y su estudio revela múltiples datos sobre los significados artísticos e ideológicos, de los que es vehículo transmisor» ${ }^{4}$.

El mundo simbólico es un conjunto de emblemas y cada emblema estructurado en tres partes -llamados emblema triplex, es decir, formado por tres elementos: cuerpo del emblema o pictura (grabado o imagen descrita con palabras), lema o inscriptio (frase generalmente en latín) y suscriptio (frecuentemente en verso o un comento, en el caso de Picinelli, en prosa, que explica y enumera los significados de los símbolos extraídos del «mundo natural» y del «mundo artificial» de los cuales el hombre podría obtener enseñanzas morales)-.

En relación con las imágenes del Mundus Symbolicus, se puede decir que sus picturae son verbales, es decir, se describen con palabras y los lectores/receptores son los encargados de construirlas mentalmente; por esta razón, son escasos y, en cierto sentido, superfluos los grabados que acompañan a la obra ${ }^{5}$. Por otra parte, habría que mencionar que esta enciclopedia en italiano está constituida por 6.130 emblemas (que corresponden más o menos al número de las imágenes verbales), mientras que en la traducción al latín aumenta a unos 7.010 emblemas. Este incremento se explica por la edición del texto que Augustinus Erath realizó al traducir y por los criterios que empleó para la traducción; entre estos sobresale su deseo de completar el texto de Picinelli y, por ejemplo, es así como añade al libro III sobre los Dioses, héroes y hombres dos apartados referentes al Antiguo Testamento y Nuevo Testamento, además de cientos de emblemas desperdigados a lo largo de la obra. Todo este arsenal iconográfico y simbólico, sirvió, por un lado, a predicadores, poetas, pintores, escultores, artistas y profesores de retórica, entre otros destinatarios, para sus creaciones plásticas y literarias; $\mathrm{y}$, por el otro, actualmente servirá a los estudiosos del arte y de la literatura para realizar análisis más certeros de las obras producidas entre los siglos XVII y principios del XIX.

4 MÍNGUEZ CORNELLES, V., Emblemática y cultura simbólica en la Valencia Barroca (jeroglíficos, enigmas, divisas y laberintos), Valencia, Edicions Alfons El Magnànim, 1997, p. 15

5 Es importante señalar que, en la versión italiana, el número y los grabados varía de acuerdo a cada edición; hay algunos que se mantienen en todas las ediciones italianas y que, inclusive, se encuentran en la versión latina. En cambio, en la versión latina se mantienen los mismos grabados en todas sus ediciones. 
Como a continuación se muestra, esos predicadores y artistas recurrieron a la literatura emblemática y, en particular, a la enciclopedia de Filippo Picinelli con la finalidad de concebir los programas iconográficos, literarios e ideológicos que se utilizaron en las piras funerarias, en los arcos de triunfo, en los carros alegóricos, en las poesías creadas para los certámenes literarios, en la oratoria civil y sagrada, en la fiesta, etcétera. Esta última fue el recinto en donde se articularon y adquirieron significados todas estas manifestaciones simbólicas. La ciudad entera mediante las fiestas celebraba el preñado, nacimiento y las bodas de la realeza; lloraba en los funerales de los reyes; celebraba las entradas triunfales de reyes y virreyes; oraba fervorosamente en el Corpus Christi y en las fiestas patronales; $y$, finalmente, deliberaba en las justas poéticas. En la vida cotidiana la literatura emblemática también estuvo presente en los enseres de casa y palacios, en la pintura mural y de caballete, en los tapices, en los biombos, en los azulejos, en altos y bajos relieves que adornaban iglesias, conventos, casas y palacios. En este momento es importante señalar que la literatura emblemática se convirtió en un saber ampliamente difundido y en una forma eficaz de educar y adoctrinar a todos los grupos sociales, tanto para fortalecer su fe cristiana como para reafirmar sus lazos de lealtad con la monarquía hispánica.

Por lo anteriormente expuesto, vale la pena destacar que, por el carácter emblemático y el contenido tan variado de El mundo simbólico, ha sido necesario para llevar a cabo la traducción, edición y estudio de la obra, abordar esta investigación desde una perspectiva interdisciplinaria y con herramientas que involucren, en primer término, a disciplinas como la filología latina e itálica, la literatura desde la Antigüedad hasta por lo menos el siglo XVII, el análisis del discurso, la retórica, la historia del arte, la historia de la cultura y, en segundo término, a otras especialidades, como la musicología e historia de la ciencia, que nos permitan traducir correctamente la diversidad de temas que constituyen la polifacética obra en cuestión.

\section{Acerca de la traducción}

La primera traducción del Mundus Symbolicus al español que realiza el equipo de trabajo de El Colegio de Michoacán y de las otras instituciones participantes, permitirá al lector moderno entrar en contacto con la literatura emblemática y disponer, al mismo tiempo, de un importante instrumento de consulta para descifrar los significados de los símbolos empleados en la producción artística novohispana y para entender el contexto cultural y religioso que rodeó e influyó a los autores de dichas obras. Así pues, El mundo simbólico es una 
indispensable vía de acceso a los sentidos latentes en la producción artística del Viejo y Nuevo Mundo de los siglos XVII, XVIII y parte del XIX.

Para la traducción al español empleamos la edición latina publicada en Coloniae Agrippinae en 1729, porque fue esta la versión que circuló profusamente en Europa y América, y, en especial, en la Nueva España, y además, cuando fue necesario para la traducción, se cotejó con la tercera edición del texto en italiano de Mondo simbolico editado en Milán en 1680. En cuanto al diseño editorial de El mundo simbólico, se quisieron recuperar algunas características del libro impreso, como la colocación marginal de las notas bibliográficas y temáticas; además, se conservaron los poemas latinos e italianos en su lengua original para brindar al lector moderno la belleza, «gusto y gracia» de ellos; y los grabados se publican en su tamaño original los cuales abarcan una página completa (Fig. 3). Otro elemento significativo en la publicación es la incorporación de diversos grabados que ilustran las imágenes descritas verbalmente por Picinelli. Para las portadas de los libros generalmente se han seleccionado pinturas novohispanas y muchas de ellas con elementos de la emblemática.

Actualmente El Colegio de Michoacán publica la traducción al español de El mundo simbólico de Filippo Picinelli en 17 tomos, distribuidos en 23 volúmenes de los cuales han aparecido:

Tomo 1: Los cuerpos celestes (libro I), traducción de Eloy Gómez Bravo, introducciones de Eloy Gómez Bravo, Herón Pérez y Carlos Herrejón, 1997.

Tomo 2: Los cuatro elementos (libro II), traducción de Eloy Gómez Bravo y Rosa Lucas González, introducción de Eloy Gómez Bravo, 1999.

Tomo 3: Dioses, héroes y hombres de la Antigüedad Clásica (libro III. Primera parte), traducción de Rosa Lucas González, introducción de E. Gabriel Sánchez Barragán, 2013.

Tomo 4: Las aves y sus propiedades (libro IV), traducción de Eloy Gómez Bravo, introducción de Bárbara Skinfill, 2012.

Tomo 7: Serpientes y animales venenosos (libro VII), traducción de Rosa Lucas, introducción de Jaime Cuadriello y Los insectos, traducción de Eloy Gómez Bravo, introducción de Elena Estrada de Gerlero, 1999.

Tomo 11: Los metales (libro XIII), traducción de Pascual Guzmán de Alba, introducción de Víctor Mínguez y Los instrumentos eclesiásticos (libro XIV), traducción e introducción de Alberto Carrillo Cázares, 2006 (Fig. 4).

Tomo 13: Los instrumentos mecánicos (libro XVII), traducción de Rosa Lucas, introducción de Agustín Jacinto Zavala y Los instrumentos de juego (libro 
$X V I I I)$, traducción de Eloy Gómez Bravo, introducción de Sagrario López Poza, 2012.

Tomo 15, 2: Los instrumentos militares (libro XXII), traducción de Rosa Lucas González, introducción de Héctor Santiesteban Oliva, 2018.

Tomo 16: Los instrumentos musicales (Libro XXIII), traducción de Eloy Gómez Bravo, introducción de Lucero Enríquez y Los instrumentos agricolas ( $\mathrm{Li}$ bro XXIV), traducción de Heriberto Moreno, introducción de Salvador Álvarez, 2017.

Hasta el momento se cuenta con la traducción de los libros: III, 2, El Antiguo Testamento; X, Las hierbas; XV, Los instrumentos domésticos; XVI, Los edificios y sus propiedades, y con la traducción parcial de los libros III, 3, El Nuevo Testamento y V, Los cuadrúpedos y sus propiedades. Por último, se publicará próximamente el libro IX, Los árboles, frutos y sus propiedades con un estudio introductorio a cargo de José Julio García Arranz y Rafael García Mahíques.

\section{Otros logros del Proyecto}

Como parte de las actividades de difusión del Proyecto Mundus Symbolicus se realizaron dos exposiciones de libros antiguos: «El Mundus Symbolicus de Filippo Picinelli en el Fondo Especial de la Biblioteca Luis González», organizada por Bárbara Skinfill Nogal para conmemorar los XXV años de la fundación del Centro de Estudios de las Tradiciones, en la Biblioteca Luis González, El Colegio de Michoacán, 13-28 de noviembre de 2008 (Fig. 5); y las «Imágenes de los Cuerpos Celestes. La Astronomía en la Literatura Emblemática del Fondo Especial de la Biblioteca Luis González», 2009: Año Internacional de la Astronomía, organizada junto con un ciclo de conferencias por Rosa Lucas González y Bárbara Skinfill Nogal, Centro de Estudios de las Tradiciones, Biblioteca Luis González, El Colegio de Michoacán, 20 de julio-25 de agosto de 2009 (Fig. 6). De igual forma, se propuso la publicación de una sección temática titulada: «Literatura emblemática. Balances, perspectivas y continuidades» en la revista de nuestra institución Relaciones. Estudios de historia y sociedad, núm. 119, vol. xxx (verano, 2009), El Colegio de Michoacán impulsada por su entonces director Herón Pérez Martínez (Fig. 7).

Por otra parte, además de la traducción, el Proyecto Mundus Symbolicus, ha estimulado el estudio de la emblemática entre investigadores de distintas disciplinas y se han propiciado espacios de discusión académica. Así, en el año de 1994 se realizó el Primer Coloquio de Verano: «El lenguaje simbólico 
novohispano en torno al Mundus Symbolicus de Filippo Picinelli» en El Colegio de Michoacán, como apoyo a nuestra labor de traducción e investigación, donde se abordaron varios temas, tales como: El Mundus Symbolicus de Filippo Picinelli, el lenguaje simbólico en Esquivel y Vargas, el emblema como sistema semiótico, el lema en el sermón novohispano, en torno a la teoría del símbolo, símbolo y cultura, la retórica del lema, etcétera (Fig. 8).

En febrero de 1997 se realizó el «Segundo Coloquio de Emblemática en torno a Filippo Picinelli: Las dimensiones del arte emblemático», en el que se examinaron la dimensión textual del emblema, las fuentes de la literatura emblemática, la emblemática novohispana, la emblemática en el arte y los simbolismos en el Mundus Symbolicus. Este segundo coloquio contó con la participación de investigadores de diversas áreas procedentes de estas instituciones: Dirección de Estudios Históricos del INAH, El Colegio de México, El Colegio de Michoacán, las Universidades: Autónoma Benito Juárez de Oaxaca, de Zacatecas, de las Américas, de La Coruña, de Londres, de Málaga, Iberoamericana, Jaume I y Nacional Autónoma de México (Fig. 9).

En febrero del 2000 El Colegio de Michoacán con apoyo del Consejo Nacional de Ciencia y Tecnología (Proyecto 26523-H) convocó al «III Coloquio Internacional de Emblemática Filippo Picinelli: Esplendor y ocaso de la cultura simbólica». Este tercer coloquio reunió a destacados investigadores que examinaron el estado de la emblemática hoy, la poética del silencio, los ecos emblemáticos en la obra de Juan Ruiz de Alarcón y en la poesía barroca, la importancia del monstruo en el programa de la alquimia emblemática, el uso de la emblemática en las pinturas murales de Tunja y en un programa catedralicio, las fuentes literarias de El mundo simbólico, el impacto de Picinelli en la obra de Luis Pueyo y Abadía; y la manifestación de la emblemática en los ámbitos públicos y privados de la Nueva España, entre otros temas. Las instituciones que participaron en este coloquio son: Benemérita Universidad Autónoma de Puebla, CONACYT, El Colegio de México, El Colegio de Michoacán, Instituto Nacional de Antropología e Historia, Secretaría de Cultura (Puebla), Universidad Autónoma de Baja California Sur, Universidad Autónoma del Estado de México, Universidad de Guadalajara, Universidad Iberoamericana, Universidad Nacional Autónoma de México, Universidad Panamericana, Holy Cross College of Worcester (Estados Unidos), Universidad de Málaga (España), Universidad de Salamanca (España), Universitat Jaume I (España). Fruto de las reuniones académicas organizadas dentro del Proyecto Mundus Symbolicus es 
la colección «Emblemata. Estudios de Literatura Emblemática», que nace y se nutre a partir de estas ${ }^{6}$.

En 1998, el Proyecto Mundus Symbolicus, con apoyo del Consejo Nacional de Ciencia y Tecnología (proyecto 26523-H) formó el Seminario de Emblemática Filippo Picinelli, grupo de trabajo interdisciplinario e interinstitucional que reunió periódicamente a investigadores, profesores y alumnos mexicanos y extranjeros interesados en el estudio del impacto y de la difusión de la literatura emblemática en diversos ámbitos culturales de Europa y de América de los siglos XVI, XVII, XVII y principios del XIX. (Fig. 10)

Este espacio académico tuvo la finalidad primordial de estimular un continuo trabajo multidisciplinario encaminado a estudiar, analizar y profundizar en todas las manifestaciones emblemáticas a través de un seguimiento a las investigaciones que se generaron dentro y fuera del seminario en el ámbito nacional e internacional. Este grupo de trabajo, Seminario de Emblemática Filippo Picinelli, se mantuvo durante seis años en los cuales se celebraron cinco seminarios (dos celebrados en 1998, uno en 2001, otro en 2002 y en 2004).

Si bien el seminario surgió como un espacio de reflexión y discusión en torno a Filippo Picinelli y a su obra El mundo simbólico, desde un principio estuvo abierto a otras líneas de investigación relacionadas con la literatura emblemática y con sus manifestaciones. Entre las líneas de investigación desarrolladas podemos mencionar, entre otras, la encargada de analizar el impacto de la literatura emblemática y el desarrollo de una cultura simbólica en la Nueva España; la interrelación entre texto e imagen y la cultura emblemática; la emblemática y su estudio interdisciplinario; las fuentes de la literatura emblemática; los espacios en que se desarrolló la cultura simbólica, etcétera. Además, gracias a la participación de especialistas en literatura, historia del arte y emblemática hispánica se han podido establecer puntos de comparación entre las fuentes, las manifestaciones y las etapas de desarrollo de la cultura simbólica tanto en España como en América y, en el caso que nos ocupa, en la Nueva

6 En esta colección se han publicado los siguientes libros: PÉREZ MARTÍNEZ, H. y SKINFILL NOGAL, B. (eds.), Esplendor y ocaso de la cultura simbólica (Emblemata. Estudios de Literatura Emblemática), Zamora, El Colegio de Michoacán / Consejo Nacional de Ciencia y Tecnología, 2002; SKINFILL NOGAL, B. y GÓMEZ BRAVO, E. (eds.), Las dimensiones del arte emblemático (Emblemata. Estudios de Literatura Emblemática), Zamora, El Colegio de Michoacán / Consejo Nacional de Ciencia y Tecnología, 2002; PÉREZ MARTÍNEZ, H. y SKINFILL NOGAL, B. (eds.), Creación, función y recepción de la literatura emblemática (Emblemata. Estudios de Literatura Emblemática), Zamora, El Colegio de Michoacán, 2012; y PÉREZ MARTÍNEZ, H. y SKINFILL NOGAL, B. (eds.), Los espacios de la emblemática (Emblemata. Estudios de Literatura Emblemática), Zamora, El Colegio de Michoacán, 2014. 
España, con lo que se han establecido puntos de confluencia, continuidades y diferencias entre la metrópoli y sus colonias.

Considero que el Seminario de Emblemática Filippo Picinelli ha contribuido ampliamente a la vinculación y al intercambio académico, a la formación de recursos humanos, a la estimulación y difusión de los estudios sobre literatura emblemática. Asimismo, nuestras investigaciones-traducciones se han beneficiado con la colaboración de otros especialistas de la emblemática, puesto que han encontrado excelentes interlocutores a fin de llevar a buen término la traducción, la edición y el estudio de El mundo simbólico en español; y, lo más notable del seminario, fue que se convirtió en el punto de confluencia de muchos esfuerzos y empeños académicos que se hallaban dispersos ${ }^{7}$.

Para concluir, me gustaría citar unas palabras del maestro Eloy Gómez Bravo sobre el desarrollo del Proyecto de traducción del Mundus Symbolicus de Filippo Picinelli: este ha vivido «de luna creciente, de luna menguante e inclusive estuvo a punto del eclipse total, pero hoy parece haber resurgido con pleno vigor y dispuesto a llegar hasta el final de su larga carrera sano y salvo en manos de las personas encargadas actualmente de terminarlo» ${ }^{8}$.

\section{BIBLIOGRAFÍA}

FRANCO MENDOZA, M. (ed., introd., transcrip. y cotejo), Diálogo de doctrina christiana en la lengua de Mechuacan (1559), Zamora, El Colegio de Michoacán, 2006 (edición en CD).

GILBERTI, M., Vocabulario en lengua de Mechuacán (ed. y transcrip. de Agustín Jacinto ZAVALA), Zamora, El Colegio de Michoacán / Fideicomiso Teixidor, 1997.

GÓMEZ BRAVO, E., «El proyecto de investigación Mundus Symbolicus en El Colegio de Michoacán», en SKINFILL NOGAL, B. y GÓMEZ BRAVO, E. (eds.), Las dimensiones del arte emblemático (col. Emblemata. Estudios

7 Por ejemplo, el «Seminario de Estudios del Siglo de Oro» (SELSO), orientado al estudio y a la recepción de la Literatura Clásica en el mundo hispánico con sede en el Instituto de Investigaciones Filológicus de la UNAM. Actualmente es coordinado por Raquel Barragán Aroche, Fernando Ibarra Chávez y Andrés Iñigo Silva, van en el XV Seminario de Estudios Literarios del Siglo de Oro (semestral). Se está llevando a cabo por todos los miembros del Seminario la revisión y el comentario de la traducción del italiano al español de Il cannocchiale aristotelico de Emmanuel Tesauro (editio princeps Torino, 1654) realizada por Fernando Ibarra Chávez. Van muy adelantados en la traducción y revisión de la obra. Esta obra es imprescindible para el estudio de la retórica, la emblemática y la literatura del Siglo de Oro y será una importante herramienta de trabajo para los investigadores hispanohablantes.

8 GÓMEZ BRAVO, E., op. cit., p. 91. 
de Literatura Emblemática), Zamora, El Colegio de Michoacán / Consejo Nacional de Ciencia y Tecnología, 2002.

«LITERATURA EMBLEMÁTICA. Balances, perspectivas y continuidades» dossier monográfico en Relaciones. Estudios de Historia y Sociedad, $\mathrm{n}^{\mathrm{o}}$ 119, vol. xxx, 2009, pp. 11-132.

LUCAS GONZÁLEZ, R. (introd., ed., trad. y notas), Grammatica Maturini, Zamora, El Colegio de Michoacán, 2003.

MÁRQUEZ JOAQUÍN, P. (trad., pres. y notas), Thesoro spiritual en lengua de Mechuacan, Zamora, El Colegio de Michoacán / Fideicomiso Teixidor, 2004.

MÍNGUEZ CORNELLES, V., Emblemática y cultura simbólica en la Valencia Barroca: (jeroglíficos, enigmas, divisas y laberintos), Valencia, Edicions Alfons El Magnànim, 1997.

MONZÓN, C. (transcrip., ed. y notas), Arte de la lengua en Mechuacán, Zamora, El Colegio de Michoacán / Fideicomiso Teixidor, 2004

MURILlO VELARDE, P., Curso de derecho canónico hispano e indiano (trad., ed. y coord. del proyecto: Alberto CARRILLO), Zamora, El Colegio de Michoacán / Facultad de Derecho de la UNAM, 2004-2005 (4 vols.) (obra completa en Curso de derecho canónico hispano e indiano, Zamora, El Colegio de Michoacán, 2008, edición en CD).

PÉREZ MARTÍNEZ, H. y SKINFILL NOGAL, B. (eds.), Esplendor y ocaso de la cultura simbólica (col. Emblemata. Estudios de Literatura Emblemática), Zamora, El Colegio de Michoacán / Consejo Nacional de Ciencia y Tecnología, 2002.

PÉREZ MARTÍNEZ, H. y SKINFILL NOGAL, B. (eds.), Creación, función y recepción de la literatura emblemática (col. Emblemata. Estudios de Literatura Emblemática), Zamora, El Colegio de Michoacán, 2012.

PÉREZ MARTÍNEZ, H. y SKINFILL NOGAL, B. (eds.), Los Espacios de la emblemática (col. Emblemata. Estudios de Literatura Emblemática), Zamora, El Colegio de Michoacán, 2014.

SKINFILL NOGAL, B. y GÓMEZ BRAVO, E. (eds.), Las dimensiones del arte emblemático (col. Emblemata. Estudios de Literatura Emblemática), Zamora, El Colegio de Michoacán / Consejo Nacional de Ciencia y Tecnología, 2002. 


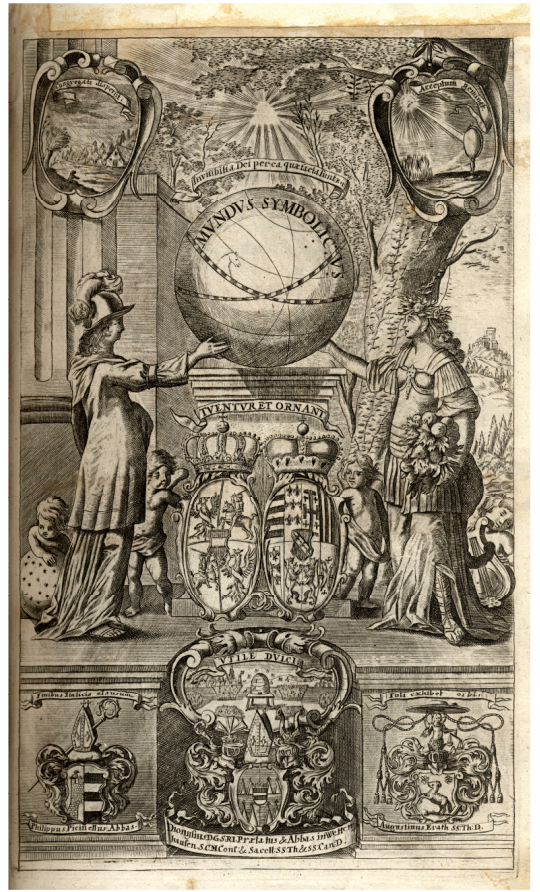

Fig. 2. Portada, Filippo Picinelli, Mundus Symbolicus (Coloniae Agrippinae, 1729), t. I. Fondo Especial, Biblioteca Luis González, El Colegio de Michoacán.
Fig. 1. Frontispicio, Filippo Picinelli, Mundus Symbolicus (Coloniae Agrippinae, 1729), t. I. Fondo Especial, Biblioteca Luis González, El Colegio de Michoacán.

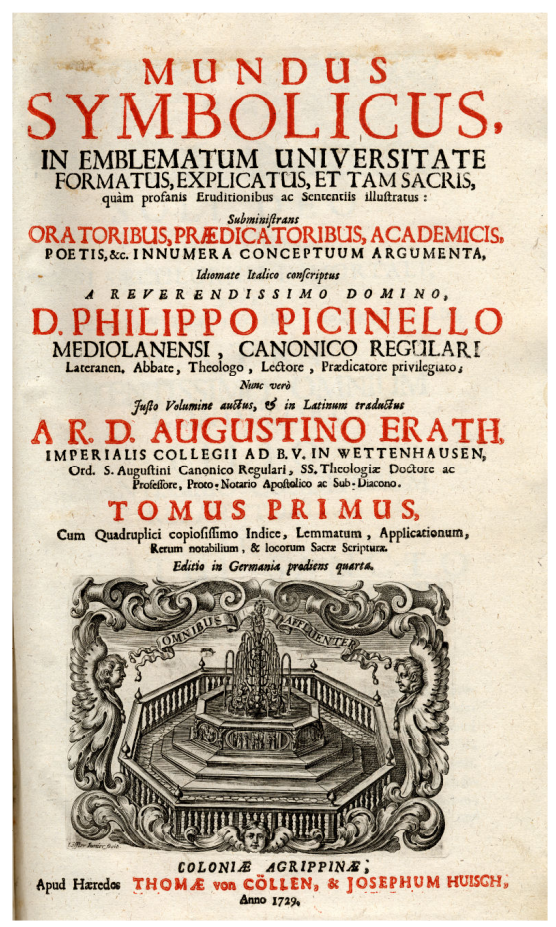




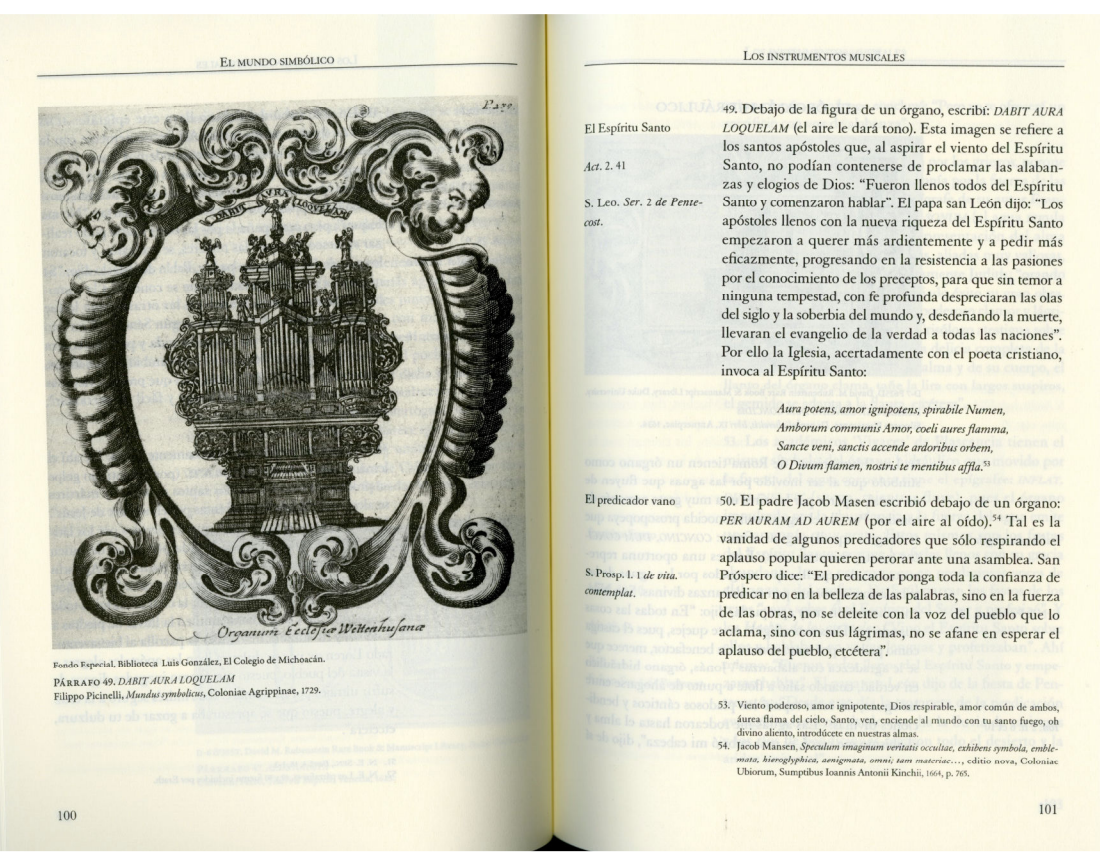

Fig. 3. Diseño editorial, Filippo Picinelli, El mundo simbólico, t. 16.

Fig. 4. Filippo Picinelli, El mundo simbólico.

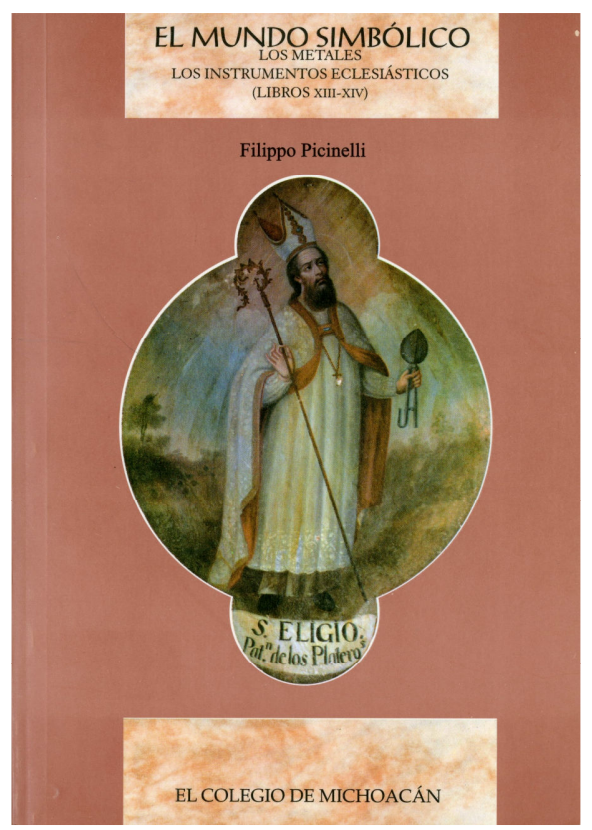




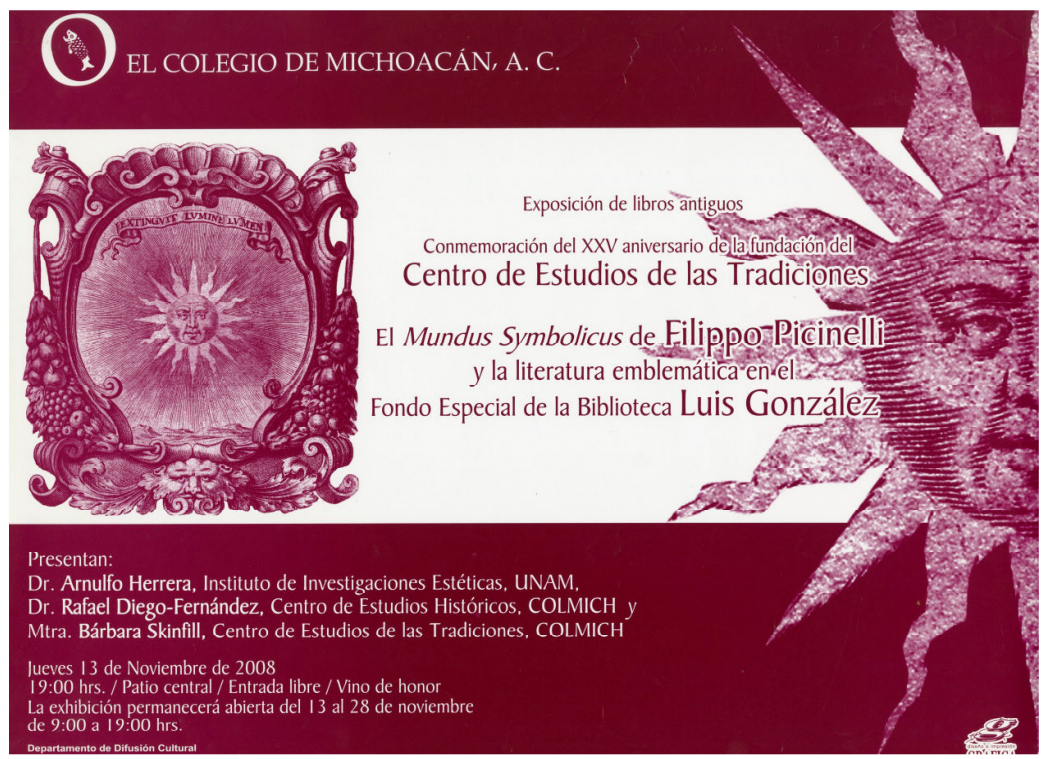

Fig, 5. Exposición de libros antiguos "El Mundus Symbolicus de Filippo Picinelli en el Fondo Especial de la Biblioteca Luis González”, XXV Aniversario de la Fundación del Centro de Estudios de las Tradiciones.

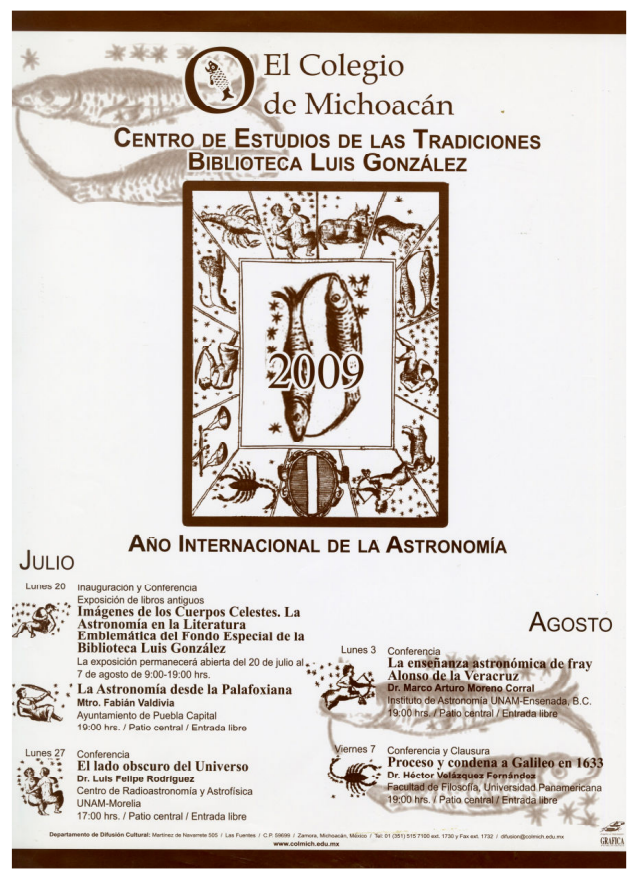

Fig. 6. Exposición de libros antiguos "Imágenes de los Cuerpos Celestes. La Astronomía en la Literatura Emblemática del Fondo Especial de la Biblioteca Luis González", 2009: Año Internacional de la Astronomía. 


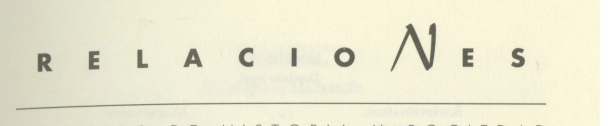

ESTUDIOS DE HISTORIA Y SOCIEDAD NÚMERO 1, VERANO 2009

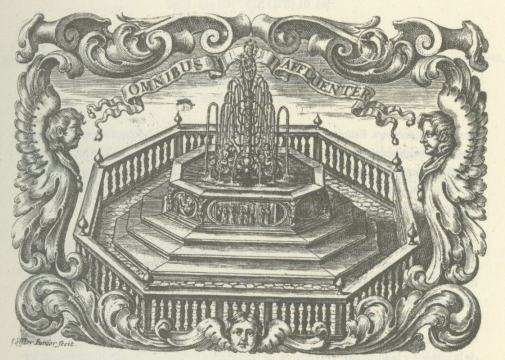

Literatura emblemática

Balances, perspectivas y continuidades

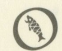

EL COLEGIO DE MICHOACÁN
Fig. 7. Sección temática sobre la "Literatura emblemática. Balances, perspectivas y continuidades", Relaciones. Estudios de historia y sociedad, núm. 119 , vol. xxx (verano, 2009), El Colegio de Michoacán.

Fig. 8. Programa del Primer Coloquio de Verano "El lenguaje simbólico novohispano en torno al Mundus Symbolicus de Filippo Picinelli”, El Colegio de Michoacán.

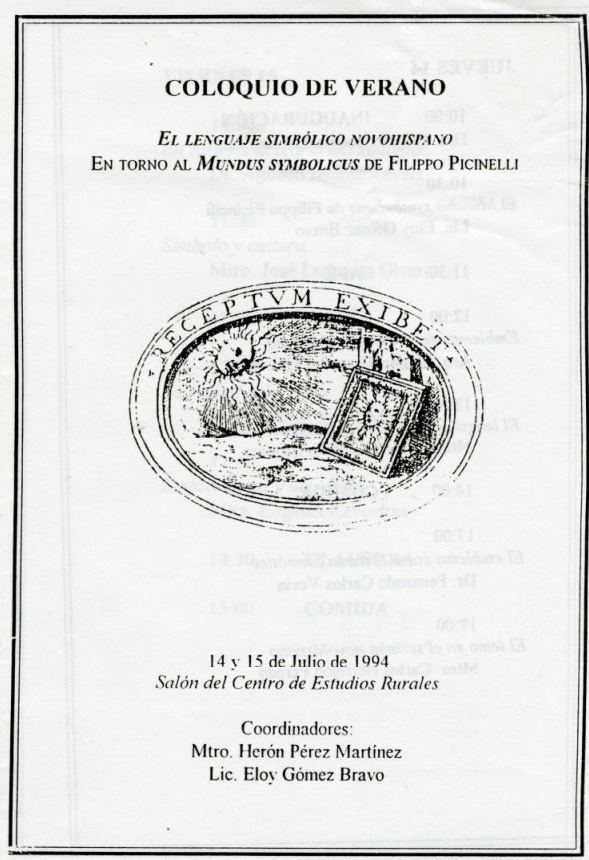




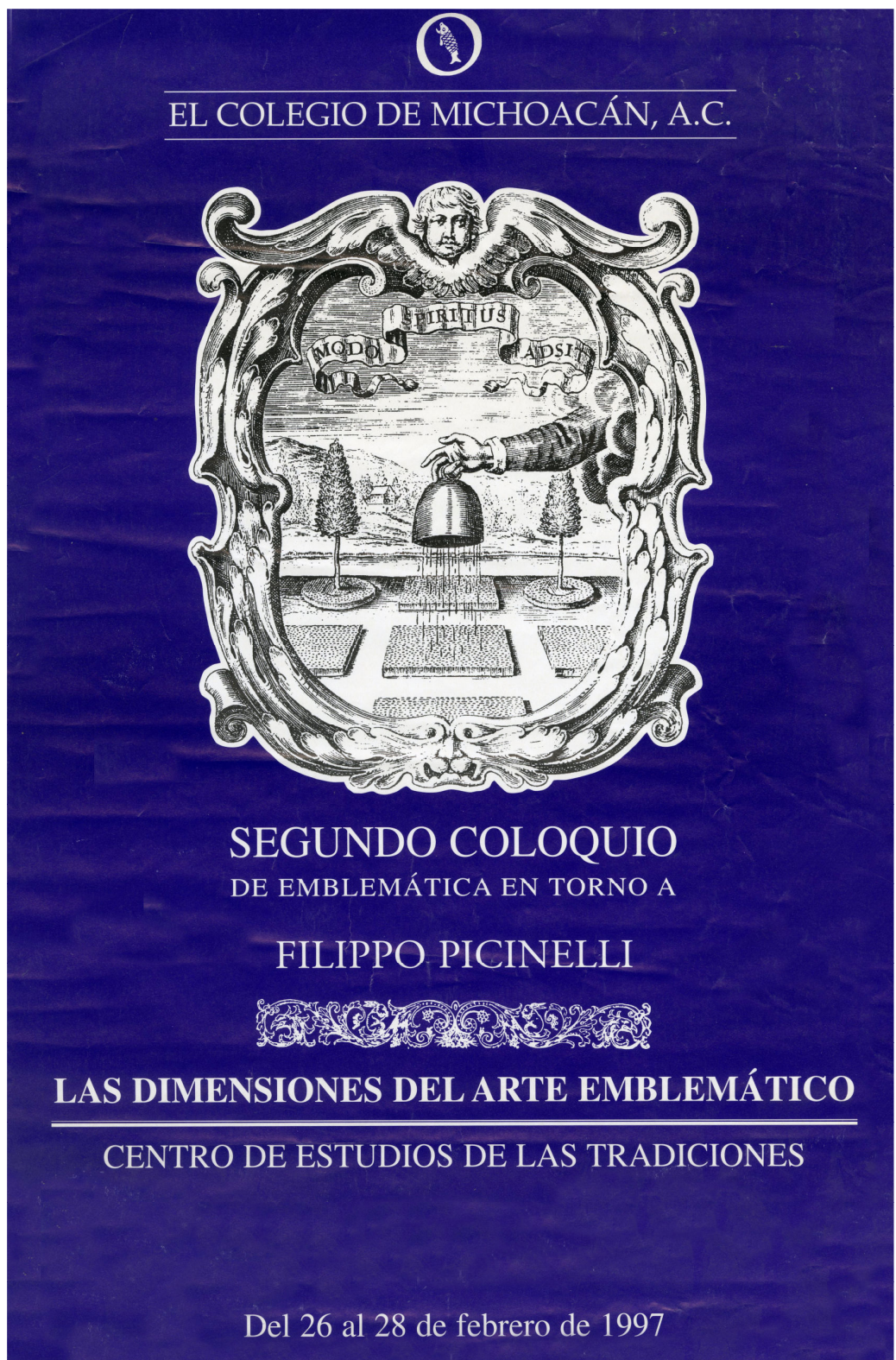

Fig. 9. Cartel del Segundo Coloquio de Emblemática en torno a Filippo Picinelli, El Colegio de Michoacán. 


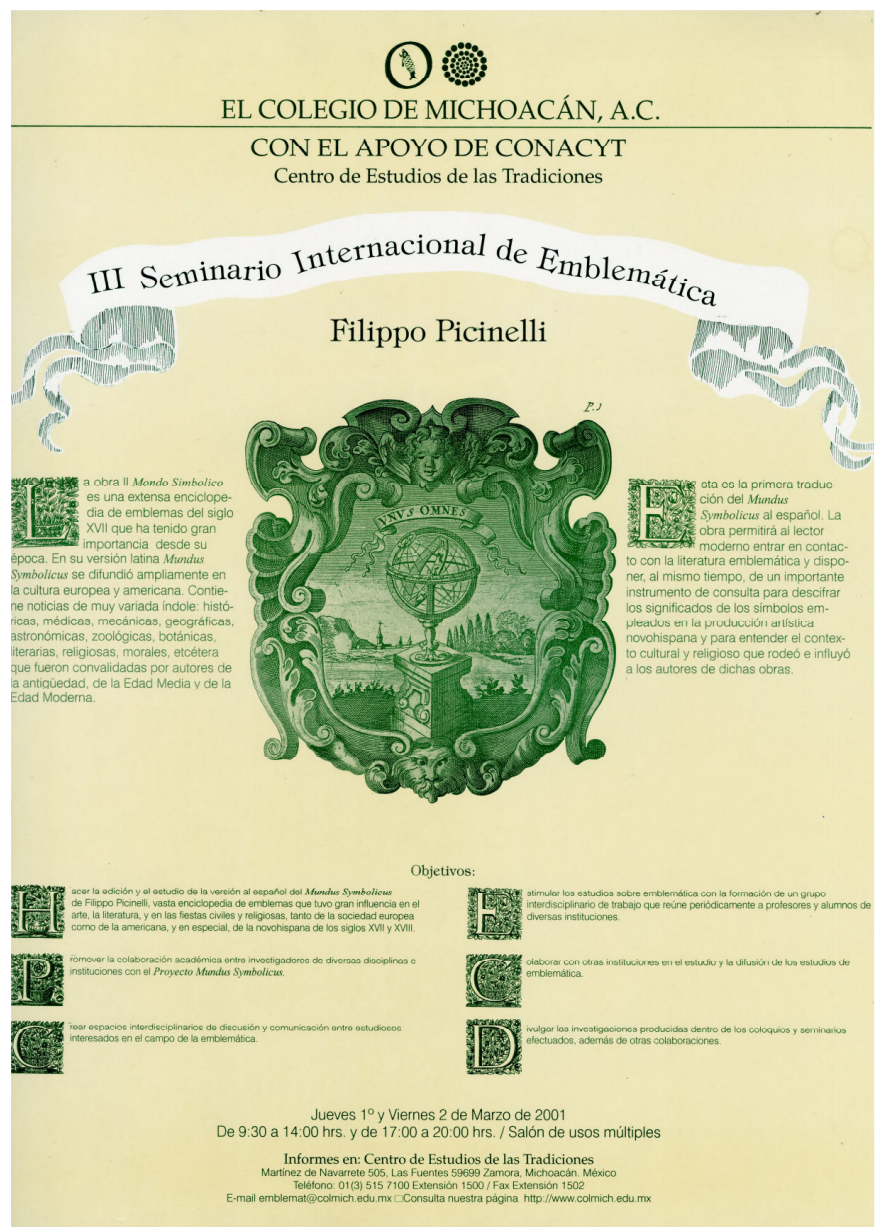

Fig. 10. Cartel del III Seminario Internacional de Emblemática Filippo Picinelli, El Colegio de Michoacán con apoyo de Consejo Nacional de Ciencia y Tecnología $(26523 \mathrm{H})$.

Bárbara Skinfill Nogal

Centro de Estudios de las Tradiciones El Colegio de Michoacán, AC Martínez de Navarrete 505, Col. Las Fuentes, C.P. 59699, Zamora, Michoacán, México https://www.colmich.edu.mx/ https://orcid.org/0000-0002-4703-860X skinfill@colmich.edu.mx 